\title{
REGULATION IN HAPPYVILLE ${ }^{1}$
}

\author{
François Salanié \\ Nicolas Treich \\ Toulouse School of Economic (LERNA-INRA), France
}

March 7, 2008

\footnotetext{
${ }^{1}$ We thank the Editor and the two referees as well as David Bardey, Timothy Besley, Yann Bramoullé, Patrick Gonzales, Kevin Haninger, Bruno Jullien, Jack Marshall and Bernard Salanié for comments. We also thank audiences at the Universities of Toulouse, Iowa State, Santa Barbara, Wageningen, Nottingham, Lille, Grenoble, Montréal-Uqam and Harvard. Corresponding author: Nicolas Treich,ntreich@toulouse.inra.fr.
} 


\begin{abstract}
How does risk perception affect risk regulation? Happyville is a society in which citizens wrongly believe that the drinking water supply is contaminated. We discuss the condition under which a benevolent Director of Environment Protection would invest in a water cleanup technology. This holds if the Director is populist, namely if he maximizes social welfare based on citizens' pessimistic beliefs that the drinking water supply is contaminated. However, investment in the water cleanup technology may also occur if the Director is paternalistic, in the sense that he maximizes social welfare based on his own beliefs while accounting for how citizens will respond to the regulation. More generally, we derive and interpret conditions such that risk misperceptions justify systematic over-regulation of risks.
\end{abstract}

Key-words: Risk Regulation, Misperception of Probabilities, Paternalism.

JEL Classification: D81, D78, H51 


\section{Introduction}

Citizens often hold beliefs about risks that systematically differ from the observed frequencies of those risks and from experts' beliefs (Camerer, 1995, Margolis, 1996). For instance, a study developed in the 1980s by the United States Environmental Protection Agency (EPA) showed that lay people ranked most environmental risks differently from EPA experts (Allen, 1987). ${ }^{1}$ These differences in risk perceptions may be related to the well-documented tendency of citizens to overestimate risks with small probabilities, or risks that have received significant media attention (Kahneman et al., 1982, Slovic, 2000).

There is also evidence of a great deal of variability in public prevention expenditures across different risks. Specifically, most regulations issued by the EPA in the last three decades have an implicit cost per life saved higher than $\$ 10$ million, and often a much higher figure (Viscusi, 1998). In contrast, studies based on individuals' willingness-to-pay usually obtain a value of a statistical life ranging from $\$ 1$ to $\$ 10$ million. $^{2}$ These observations suggest that there has been a persistent over-regulation of environmental risks in the United States. ${ }^{3}$ The example of hazardous waste sites is especially striking

\footnotetext{
${ }^{1}$ In particular, lay people ranked the highly publicized risk from hazardous waste sites as the most serious risk, while this risk was only ranked medium or low risk by EPA experts.

${ }^{2}$ See for instance Viscusi and Aldy (2003). Moreover, a much lower implicit cost per life (or life-year) saved is usually found for health care, transportation or occupational prevention programs compared to environmental protection programs (Tengs at al., 1995).

${ }^{3}$ See, e.g., Hahn (1996). It is difficult to find similar data about the efficiency of risk policies for european countries, probably as the use of benefit-cost analysis is less developed
} 
in this respect, with a cost per life saved of the Superfund program estimated to be more than $\$ 1$ billion. ${ }^{4}$

Putting together these two bodies of evidence suggests that risk regulators respond to citizens' beliefs about risks. For instance, Sunstein (2000) observes that "EPA policies track ordinary judgments extremely well", and that "the government currently allocates its limited resources poorly, and it does so partly because it is responsive to ordinary judgments about the magnitude of risks" (Sunstein, 2000, p. 227). Regulators may respond to citizens' beliefs by political opportunism, or simply because they have similar perception biases. Notice that regulators' responsiveness is an expression of wellfunctioning deliberative democracies, and is in a sense perfectly legitimate. But is it economically desirable?

Whether or not regulators should respond to citizens' beliefs raises a puzzling normative question. This question is well illustrated by the Happyville fable. ${ }^{5}$ Happyville is a society in which people believe that the drinking wa-

in Europe than in the United States. Hammitt et al. (2005) suggest, however, that some risks (including transport, energy and health risks) are more regulated in Europe than in the United States.

${ }^{4}$ See Viscusi and Hamilton (1999); see also the Table 1 reported in Sunstein (2000), which indicates the high implicit cost per life saved of several hazardous waste reduction programs.

${ }^{5}$ See Portney (1992), page 131: "You are Director of Environmental Protection in Happyville (...). The drinking water supply in Happyville is contaminated by a naturally occurring substance that each and every resident believes may be responsible for the aboveaverage cancer rate observed there. So concerned are they that they insist you put in place a very expensive treatment system to remove the contaminant. (...)

You have asked the top ten risk assessors in the world to test the contaminant for carcinogenicity (...). These ten risk assessors tell you that while one could never prove that the substance is harmless, they would each stake their professional reputations on its being so. You have repeatedly and skillfully communicated this to the Happyville citizenry, 
ter is contaminated while all experts agree it is harmless. Furthermore, any attempt to inform people that the water is safe has had no effect. People remain anxious and they urge the Director of Environmental Protection to invest in a water cleanup technology. What should the Director do?

Even though the Director is convinced that citizens' beliefs are erroneous, the decision of whether to invest in a water cleanup technology is a difficult one. On the one hand, consumer sovereignty arguments support the Director's decision to purchase a cleanup technology. This would improve welfare since worried people would feel protected. ${ }^{6}$ On the other hand, some scholars have arguably criticized this populist approach to risk regulation. ${ }^{7}$ They stress that regulatory decisions must be driven by risk-related facts, not by citizens' uninformed worries. There is an obvious opportunity cost here, as the money spent to prevent a phantom risk could be used for better purposes. Yet, this last approach is controversial as well, as it relies on a paternalistic view of citizens' preferences. It presumes that the regulator knows better than the citizens do about what is good for them.

This paper introduces a framework to study the problem faced by the Director of Environmental Protection in Happyville. Importantly, this framework takes into account that citizens make choices according to their beliefs and that they will react to the safety regulation. We use this framework to

but because of a deep-seated skepticism of all government officials, they remain completely unconvinced and truly frightened.".

${ }^{6}$ See Sandmo (1983) and Pollack (1995, 1998).

${ }^{7}$ See Breyer (1993), Hird (1994), Sunstein (2000) and Viscusi (2000). 
compare the outcomes of the populist policy and the paternalist policy. As we will see, both approaches may warrant more regulatory intervention when risks are misperceived. In particular, we find that the paternalist policy may always lead to over-regulation of risks no matter whether the citizens are optimistic or pessimistic. Hence, an important, and maybe unexpected, policy message of the paper is that the paternalistic approach to risk regulation may justify a systematic over-regulation of risks.

\section{The Happyville Economy}

We introduce a simple model of the Happyville economy, which we will generalize in the next section. The key feature of our model is that the citizens' beliefs about the risk related to the drinking water supply may differ from the beliefs held by the Director. We suppose for simplicity that, except from this difference, the preferences of the citizens and that of the Director are aligned.

Assume that there is a single citizen living in Happyville, with quasi-linear preferences given by

$$
U(x, a, b)=u(b)-(1-a) b x-c(a)
$$

where

$b:$ is the citizen's water consumption, $b \geq 0$,

$u(b)$ : is the citizen's gross surplus, assumed increasing and concave,

$a:$ is the Director's cleanup effort, $0 \leq a \leq 1$, 
$c(a)$ : is the per capita cleanup cost function, assumed increasing and convex, $x:$ is the unknown dose-response carcinogenicity risk.

Hence the damage is $(1-a) b x$; observe that it decreases with the cleanup effort $a$ and increases with consumption is $b$. The uncertainty bears on the value of $x$, and only the expected value of $x$ matters. Denote $s$ the expected value of $x$, when computed with the citizen's beliefs. To simplify, we call $s$ the citizen's beliefs. We assume that the Director is aware of the citizen's beliefs s. However, we allow the Director to have different beliefs about the risk, denoted $r$. A higher $s$ corresponds to a more pessimistic (respectively less optimistic) citizen when $s>r$ (respectively $s<r$ ). Throughout the paper, we will examine how the difference between $r$ and $s$ (or risk misperception) affects the cleanup effort $a$ selected by the Director.

To start with, assume that the citizen's consumption $b$ is exogenously given. We first look at the cleanup effort that would be developed by a populist Director. Define a populist Director as a regulator who maximizes the citizen's welfare computed with the citizen's beliefs s. Hence the populist chooses the cleanup effort $a$ by maximizing the objective $U(s, a, b)$, so that

$$
s b=c^{\prime}(a),
$$

that is, the marginal perceived benefit is equal to the marginal cost of the cleanup effort $a$. Clearly, if the citizen is pessimistic $(s>r)$, a populist Director will over-invest in the cleanup technology, compared to the identical 
beliefs case when $s=r$. Conversely, the populist Director will under-invest in the cleanup technology if the citizen is optimistic $(s<r)$.

What happens if the Director is paternalistic? Define a paternalist Director as a regulator who maximizes the citizen's welfare computed with his own beliefs $r$. In this case, it is easy to see that the Director's policy a does not depend on the citizen's beliefs $s$. Indeed, the paternalist Director simply maximizes over $a$ the objective $U(r, a, b)$, which yields $r b=c^{\prime}(a)$, as if there were no beliefs distortion. To sum up, when water consumption is given, the populist policy is determined by the citizen's beliefs (but neglects some valuable information) while the paternalist policy is unaffected by risk misperceptions (but ignores the citizen's worries).

Few situations are such that the citizen's risk exposure is exogenously given. The problem becomes more realistic and more interesting when consumption $b$ is not given, but may change as beliefs $s$ and the cleanup effort $a$ change. When allowing for this possibility, the citizen chooses, for a given cleanup effort $a$, his water consumption $b(a, s)$ to maximize $U(s, a, b)$, so that

$$
u^{\prime}(b(a, s))=(1-a) s
$$

According to the intuition, water consumption $b(a, s)$ is decreasing in the perceived probability of getting cancer $s$ and increasing in the level of cleanup effort $a$.

The populist criterion now corresponds to the citizen's welfare computed with beliefs $s: U(s, a, b(a, s))$. On the other hand, the paternalist criterion is 
$U(r, a, b(a, s))$, and we denote $a(r, s)$ a maximizer of this expression. As before, the only difference between the two criteria is that the populist Director uses the citizen's beliefs $s$ while the paternalist Director uses his own beliefs $r$. Observe, however, that the fact that the citizen's consumption $b(a, s)$ is endogenous introduces a new subtlety into the analysis. The paternalist Director needs to account for the citizen's actual response, i.e., the response based on $s$, not on $r$. Clearly, maximizing instead $U(r, a, b(a, r))$ would be suboptimal for the paternalist Director, as he would not correctly anticipate the citizen's actual reaction. We will denote this last suboptimal regulatory policy $a(r, r)$ and coin it the "rationalist" policy. Observe that $a(r, r)$ corresponds to the optimal level of cleanup effort without any difference in beliefs. Hence $a(r, r)$ will be our benchmark case in the analysis; thanks to the envelope theorem, it is such that

$$
r b(a, r)=c^{\prime}(a) .
$$

To sum up, we may consider three different types of regulation. The Director may select:

$$
\begin{aligned}
& a(r, s): \text { the paternalist policy } \\
& a(s, s): \text { the populist policy } \\
& a(r, r): \text { the rationalist policy. }
\end{aligned}
$$

To illustrate, consider quadratic forms

$$
u(b)=-(1-b)^{2} / 2 ; \quad c(a)=a^{2} / 2 .
$$


Then the citizen's choice is simply $b(a, s)=1-(1-a) s,{ }^{8}$ so that we get

$$
U(r, a, b(a, s))=-((1-a) s)^{2} / 2-(1-a) r(1-(1-a) s)-a^{2} / 2 .
$$

Maximizing this expression over $a$ gives the paternalist policy

$$
a(r, s)=\frac{r-2 r s+s^{2}}{1-2 r s+s^{2}}
$$

from which we derive the populist and the rationalist policies:

$$
a(s, s)=\frac{s}{1+s} ; \quad a(r, r)=\frac{r}{1+r}
$$

Figure 1 represents the three different policies as a function of the citizen's beliefs $s$. Following Viscusi (2000), we call Blissville the mirror image of Happyville, that is, a society where the citizen is optimistic.

\section{INSERT FIGURE 1 ABOUT HERE}

Since the rationalist policy $a(r, r)$ does not take into account the citizen's beliefs, it is a straight line on the figure. By contrast, the populist policy ignores the objective risk $r$, and is monotonically increasing with $s$. According to the intuition, the populist policy responds to citizens' worries.

Finally, let us turn to the paternalist policy. From equation (5), the decision $a(r, s)$ is decreasing in $s$ then increasing in $s$. This function has its minimum at $s=r$. Thus we have $a(r, s) \geq a(r, r)$ : the paternalist policy is always larger than the policy undertaken under no risk misperceptions.

\footnotetext{
${ }^{8}$ For simplicity we assume away zero consumption by restricting $r$ and $s$ to be less than $u^{\prime}(0)=1$.
} 
In other words, the difference in beliefs always calls for more regulatory intervention, even under the paternalist approach, and no matter whether the citizen is pessimistic or optimistic. We examine the robustness of this result in the following section.

\section{A General Framework}

Consider the following game. A regulator decides $a$. An agent reacts to $a$ by making a decision $b$. These choices are performed under uncertainty on the true state of nature $x \in X$. The Von Neumann-Morgenstern preferences of the agent are given by the utility function $U(x, a, b)$. Because the regulator is benevolent, he shares the same preferences under certainty.

We assume that $x$ takes a finite number of values. Decisions $a$ and $b$ are real numbers. $U$ is assumed to be three times differentiable with respect to $(a, b)$, and strictly quasi-concave with respect to $b$.

Let us endow the agent with beliefs $q$, defined in the usual manner:

$$
\forall x \in X \quad q(x) \geq 0 \quad \sum_{x \in X} q(x)=1 .
$$

The agent chooses $b$ to solve

$$
\max _{b} \sum_{x \in X} q(x) U(x, a, b),
$$

whose unique solution is now denoted by $b(a, q)$. As we have explained above, a populist regulator would share the same beliefs, and thus would simply maximize this objective function with respect to $a$ to determine the optimal policy. 
Our focus in this section is mostly on the paternalistic case. Suppose that the beliefs $p$ held by the regulator differ from the beliefs $q$ held by the agent. Acting as a Stackelberg leader, the paternalistic regulator chooses his decision accordingly, by maximizing over $a$

$$
\sum_{x \in X} p(x) U(x, a, b(a, q))
$$

We now show that the paternalist decision is determined by two different effects that go in opposite directions. Differentiating with respect to $a$ the objective function in (6), one get: ${ }^{9}$

$$
\underbrace{\sum_{x \in X} p(x) U_{a}(x, a, b(a, q))}_{\text {Protection Effect }}+\underbrace{\left[\sum_{x \in X} p(x) U_{b}(x, a, b(a, q))\right] b_{a}(a, q)}_{\text {Encouragement effect }}=0 .
$$

The "protection effect" corresponds to the direct effect of the regulatory policy, namely to the change in expected utility induced by the decision $a$, keeping $b$ constant. This is the only effect that matters when the regulator and the agent share the same beliefs, since the second term is zero when $p=q$. When beliefs are different, there is a second effect that depends on the agent's response to the regulatory policy. We coin this effect the "encouragement effect," as it captures how a change in the regulatory decision may encourage the agent to react in a specific direction.

In most regular cases, the protection and the encouragement effects have opposite signs. Let us illustrate this on the Happyville example. Assume that

\footnotetext{
${ }^{9}$ Subscripts denote partial derivatives.
} 
the citizen is optimistic. Thus, from the regulator's viewpoint the citizen consumes too much water, and his exposure to cancer risk is too high. An increase in the prevention effort is thus required to reduce the probability of cancer. This is the protection effect, which is positive here. However cleaning water encourages the citizen to consume even more water, a source of disutility since the citizen consumed too much water in the first place. Hence, the encouragement effect is negative and is thus opposed to the protection effect. $^{10}$

We now examine the effect of a change in beliefs on the regulator's decisions. To do so, we need to specify what is a change in beliefs. From now on, we fix two beliefs $p$ and $q$, and analyze the regulatory policy when both the regulator's and the citizen's beliefs are allowed to vary in the interval $[p, q]$. Suppose that the regulator holds beliefs $(1-r) p+r q$, while the agent holds beliefs $(1-s) p+s q$, where $r$ and $s$ belong to $[0,1]$. An increase in $s$ then makes the beliefs more different if $s>r$, and closer otherwise. ${ }^{11}$ Define the

\footnotetext{
${ }^{10}$ Suppose for example that $U_{a b}$ is positive, so that $b(a, q)$ is increasing with $a$; and that the agent's beliefs are such that $b(a, q)>b(a, p)$ for any $a$. Since $U_{a}$ is increasing with $b$, the protection effect is positive. Moreover, the encouragement effect is negative as it is the product of a negative and a positive factor: the first factor is negative from the quasi-concavity of $U$ in $b$, and the second factor is positive because $b(a, q)$ is increasing with $a$. These effects would of course change sign if $b(a, q)<b(a, p)$ or if $U_{a b}$ was negative, but they would remain of opposite signs.

${ }^{11}$ For example, suppose that initially both the regulator and the agent share the same beliefs $p$, but an experiment is performed, giving additional information on the true state of nature. Nevertheless, there is an exogenous probability that the experiment has failed, and in that case its results are uninformative. Moreover there is no way to tell whether the experiment has failed or not. If the regulator and the agent do not agree on the probability of failure, their revised beliefs take these linear forms.
} 
paternalist regulator's expected utility as

$$
K(a, r, s)=\sum_{x \in X}[(1-r) p(x)+r q(x)] U(x, a, b(a,(1-s) p+s q)),
$$

and denote $a(r, s)$ a solution to the regulator's program $\max _{a} K(a, r, s)$.

In what follows, we vary $s$ in order to capture the effect of the difference in beliefs on $a(r, s)$. Referring to Figure 1, we say that $a(r, s)$ is U-shaped if it is increasing when $s$ moves away from $r$, in either direction. The following Proposition identifies the condition on the regulator's expected utility that ensures that $a(r, s)$ is always U-shaped.

Proposition 1 Suppose that $K_{a s}(a, 0, s)$ is non-negative, for any a and any $s \in[0,1]$. Then for any $r, s \in[0,1], a(r, s)$ is U-shaped.

To interpret this Proposition, suppose that the regulator has some beliefs $p$, and that for some beliefs $q$ the derivative $K_{a}(a, 0, s)$ increases when the agent's beliefs $(1-s) p+s q$ vary from $p$ to $q$. This condition ensures that the optimal policy $a(0, s)$ increases with $s$. Then the Proposition shows that $a(r, s)$ must be U-shaped, as in Figure 1. In that sense, monotonicity in one direction is enough to ensure that risk misperceptions call for increasing $a$, whatever the beliefs of the regulator and that of the agent in the interval $[p, q]$. Moreover, the fact that the agent is pessimistic or optimistic compared to the regulator does not matter.

Let us apply Proposition 1 to the Happyville example, as defined in (1). Because in this example only the expectation of $x$ matters, we can define $p$ 
as the beliefs that put all weight on $x=0$ : this corresponds to the most optimistic belief. Define also $q$ as the beliefs which put all weight on a high value for $x$, which we normalize to 1 . Hence the regulator believes there is no risk at all when $r=0$, while the consumer becomes more pessimistic as $s$ increases. Thanks to our definition of $p, K(a, 0, s)$ is written

$$
K(a, 0, s)=u(b(a,(1-s) p+s q))-c(a) .
$$

The protection effect reduces to $\left(-c^{\prime}(a)\right)$, and thus is independent of $s$. This is simply because the regulator believes that there is no risk at all. The encouragement effect is more complex, and writes

$$
u^{\prime}(b(a,(1-s) p+s q)) \times \frac{\partial b}{\partial a}(a,(1-s) p+s q)
$$

which is positive because consumption increases with $a$. Now when the index of pessimism $s$ increases, consumption decreases, so that the first term in (10) increases. Hence, a sufficient condition for the cleanup effort to unambiguously increase is that $\frac{\partial b}{\partial a}$ increases with pessimism $s$ (or at least does not decrease too rapidly with $s$ ). To sum up, suppose that the water consumption of the more pessimistic agent is more sensitive to cleanup efforts, then $a(r, s)$ is $\mathrm{U}$-shaped, that is, any risk misperception induces the regulator to increase his cleanup effort. The comparative static analysis thus critically depends on properties of the water demand in the society. To see that, it is convenient to define the water demand function $D(\rho)$ associated with $u$ by the well-known identity

$$
u^{\prime}(D(\rho))=\rho,
$$


where $\rho$ is the shadow price of water. After straightforward computations, ${ }^{12}$ we obtain:

Corollary 1 In the Happyville economy as defined in (1) and (11), a(r,s) is $U$-shaped if $\rho^{2} D^{\prime}(\rho)$ is non-increasing with $\rho$.

Therefore the effect of different beliefs only depends on the properties of $u$, or equivalently on the water demand function $D(\rho)$. It is thus needed that the derivative $D^{\prime}(\rho)$ does not increase too rapidly with $\rho .^{13}$

To conclude this section, we make use of this framework to examine the effect of the difference in beliefs on the populist's regulatory effort, and we relate it to the paternalistic case. The populist regulator's expected utility is defined as

$$
j(a, s) \equiv K(a, s, s) .
$$

The leads to the following Proposition.

Proposition 2 i) The populist policy $a(s, s)$ is increasing in $s$ if $j_{a s}(a, s)$ is positive, for any $a$ and $s \in[0,1]$. ii) The paternalist policy $a(r, s)$ is $U$-shaped if $j_{\text {ass }}(a, s)$ is negative, for any $a$ and $r, s \in[0,1]$.

This Proposition shows that the comparative static analysis of the difference in beliefs may be solved by only examining the properties of the value

\footnotetext{
${ }^{12}$ It is direct from (10) and (2) that the comparative statics analysis only depends on how $\frac{-u^{\prime}(b)^{2}}{u^{\prime \prime}(b)}$ varies with $b$, which is equivalent to the condition exhibited in the Corollary 1.

${ }^{13}$ This is verified by any linear demand function, as in the quadratic case we considered above, as well as by any iso-elastic demand function with elasticity less than one. Empirical works on water demand elasticity usually postulate iso-elastic demand functions, and indeed support a value below one (see, e.g., Nauges and Thomas, 2000).
} 
function $j$. Result i) needs no proof. It expresses that the marginal gain of increasing $a$ increases with $s$, so that the populist effort must also be increasing. When applied to the Happyville example, this condition reduces to $\rho D(\rho)$ increasing, or equivalently to an elasticity of water demand less than one. Indeed, if more pessimism led to a strong reduction in consumption, it would reduce, and not increase, the need for a more stringent regulation.

Result ii) derives a sufficient condition for the paternalistic regulator to increase his effort as $s$ moves away from $r$. This condition is equivalent to that derived in Proposition 1 that $\rho^{2} D^{\prime}(\rho)$ is decreasing. Observe that this condition is distinct from that obtained in the populist case. It makes it clear mathematically that ii) involves the third derivative of the objective. This condition thus relates to the sensitivity of the demand elasticity, and not only to the demand elasticity as for the populist case.

\section{Discussion}

\subsection{Explaining risk regulatory outcomes}

A growing literature has studied why the decisions of risk regulators may depart from the decisions predicted by benefit-cost analysis. Risk policies are often constrained by general principles, such as the search for equity (Viscusi, 2000), or the desire to reduce the regulator's discretion in order to avoid corruption, or the temptation to choose policies that benefit a political clientele (Cropper et al., 1992, Boyer and Laffont, 1999). Obviously, risk regulation ultimately depends on the institutions of risk management (Beck, 
1992), and their everyday functioning. And it has been suggested that bureaucratic incentives and common practices in these institutions are plagued with conservatism and status quo bias. ${ }^{14}$

There is also substantial empirical evidence that risk regulation heavily reflects citizens' risk perception biases (Breyer, 1993, Viscusi, 1998, Sunstein, 2000). It has been repeatedly observed for instance that additional safety measures are mandated in the aftermath of a flight crash, a terrorist attack, bad news about health-related food quality, a chemical plant accident, and the list could go on. Some scholars have suggested that these additional safety measures can hardly be justified using a rational basis for risk regulation. A common explanation is that these measures are a consequence of the availability heuristic that makes the risk temporarily more salient to citizens (Kahneman et al., 1982), a perception bias which is in turn embodied in policy-making by a populist regulator (Sunstein, 2000). Hence the literature usually explains this regulatory outcome by populism.

Our paper proposes a formal model which relates risk perception to risk regulation. The model encompasses the populist regulation. However, we have identified another motive for regulation, based on paternalism. It recog-

\footnotetext{
${ }^{14}$ For instance, regulators who cause undesirable outcomes by acting usually receive more blame than those who cause undesirable outcomes by not acting. Also, regulators often set a uniform safety norm based on a theoretical "maximally exposed" individual. They routinely use upper bound values of probability distributions, and apply rule-ofthumb margins of safety. As a result, regulators decisions do not pay enough attention to the real exposed population, to the best estimates of the risk and to local disparities in the cost of avoided damages. For a critical discussion of these various policy practices, see, e.g., Viscusi (1998) and Adler (2005).
} 
nizes that citizens may make faulty choices due to their biased beliefs, and that a regulator may rationally anticipate these choices and may want to curb them. Consider the fact that thousands of tourists cancel their travel plans after a flight crash or a terrorist attack, with the associated negative consequences for the economy. Our model suggests that a paternalistic regulator should respond to these events by increasing investments in safety compared to the no risk misperceptions case in order to mitigate these negative consequences. Similarly, a regulator should raise standards for food safety to prevent a drop in consumption after bad news about health-related food quality.

These remarks suggest that it may be difficult to discriminate between populism and paternalism. There are, however, two fundamental differences. First, when citizens make no decisions, remember that the paternalist regulation is not affected by citizens' beliefs, unlike the populist regulation. Hence, evidence of over- or under-regulation in this case pleads for the presence of populism. Recognizing this, the populist regulation can perhaps better explain extra safety norms imposed to chemical plants just after a plant accident, a risk for which citizens can only take limited actions.

The second difference occurs in the more realistic case in which citizens make decisions. In that case, populism usually predicts under-regulation when citizens are optimistic, while paternalism may still predict over-regulation under optimism. Hence, evidence of over-regulation combined with evidence of risk under-estimation can only be explained by paternalism in this case. 
High standards for consumer and occupational risk, as well as stringent pesticide regulation, may fall into this category.

Finally, although we do not want to embrace the proposition that all risk regulatory outcomes can be best explained by our model of either populism or paternalism, we add that this model can also capture political economy considerations. Indeed, the populist approach fits well the case of a regulator facing elections in the short-term. In this case, responding to the citizens' current demands may increase the chances that the regulator is reappointed. In the long run, however, the public will likely observe the trends of the early damages. Hence, a populist policy may face ex-post public contestation. As a consequence, a long-term regulator may prefer to adapt the prevention effort to sound information about future damages. This strategy is more in line with the paternalist approach. These observations suggest it may be interesting to relate risk regulatory outcomes to the length of regulators' political mandate, which may help to distinguish our two policy benchmarks.

\subsection{Some critical assumptions of the model}

The main assumption of the Happyville economy is that the consumer misperceives the risks he faces. Such a misperception does not necessarily imply that the consumer has a bounded rationality. Misperceptions may simply be the consequence of costly information acquisition by a rational consumer (e.g., because the information is highly technical). Yet, a second important assumption is that the consumer does not revise his beliefs, even after he 
observes the Director's cleanup effort. He may know the Director's beliefs and simply disagree with him; so that the Director's choice of $a$ has no informational content and does not lead to any revision of beliefs. Another possibility is that the consumer does not trust the Director, as in Portney's fable, and attributes the choice of $a$ to other irrelevant considerations. ${ }^{15}$ The realism of this assumption is ultimately an empirical question. Do consumers revise their beliefs when they observe the regulatory policy, or do they stick to their opinion? The answer is likely to depend on the experts' credibility, and may vary between the fully rational Bayesian model and the no-inference case that we have considered here (see also Spence, 1977).

A related assumption in the Happyville society is that the consumer's decision is based upon his own (erroneous) beliefs. Typically, from the regulator's viewpoint, optimists are over-exposed to risks and pessimists are under-exposed to risks. These suboptimal decisions may in turn affect, or even trigger, the safety policy intervention. Yet an additional aspect is that the consumer's response to the regulatory policy also depends on consumer's beliefs. Though this latter effect is probably more difficult to pin down empirically than the former effect, our analysis suggests that it should not be neglected as it may affect the whole picture. ${ }^{16}$

\footnotetext{
${ }^{15}$ Moreover, recall that the paternalist policy responds in the same qualitative way to both optimism and pessimism. So while the citizen may know from observing $a$ that his beliefs are mistaken, he does not know the direction of the mistake. Hence, it is difficult for the citizen to infer something from observing the regulator's policy.

${ }^{16}$ Few studies have analyzed the consumers' response to a change in perceived safety, and whether this response may be affected by their own risk perceptions. Interestingly, Viscusi (1998) report a correlation between child-resistant packages and an increase in accidental
} 
Also, we have considered so far a Happyville economy with only one representative consumer, or equivalently with a homogeneous population with identical beliefs. This assumption is strong, as there may be both pessimistic and optimistic consumers living in the same economy. How does heterogeneity in consumers' beliefs affect the regulatory policy? Clearly, this will matter for the populist regulator, whose preferred policy depends crucially on whether consumers are on average optimistic or pessimistic. However, it is easy to understand that beliefs heterogeneity does not change qualitatively the paternalist policy. We can easily see that in Figure 1. Observe that the effect of the beliefs distortion on the paternalist policy always goes in the same direction, and again, no matter whether people are optimistic or pessimistic. Hence, beliefs heterogeneity would not change the comparative statics analysis in that case, still leading to increase the prevention effort. In contrast, notice that heterogeneity in preferences, such as heterogeneity in the individuals' utilities, would clearly matter for both the paternalist policy and the populist policy.

A particular form of heterogeneity obtains when some consumers have biased beliefs while others have correct beliefs. An anti-paternalistic argument would then be the following. Why should consumers with correct perceptions pay for the extra prevention efforts due to other consumers' biased beliefs? This argument applies to the Happyville economy if the regulator cannot

poisonings, which he attributes to the unanticipated effect that consumers might have become less safety conscious due to the existence of safety caps. This also relates to the well-known study on car accidents and seatbelts by Peltzman (1975). 
differentiate the prevention costs across consumers. However, it can easily be seen that in the neighborhood of the benchmark cleanup effort $a(r, r)$, the gain for consumers with beliefs $s \neq r$ corresponds to a first-order effect while the loss for consumers with beliefs $s=r$ corresponds to a second-order effect. As a result, the increase in the prevention effort induces relatively little harm for consumers with correct beliefs in Happyville. ${ }^{17}$

\subsection{Other regulatory instruments}

Finally, we discuss the role of taxation in the Happyville economy. Clearly, taxing consumption is useless for a populist Director. On the other hand, a paternalist Director could set a tax so as to correct the impact of different beliefs, the optimal tax being $t^{*}=(1-a)(r-s)$. Hence, consumption is taxed if consumers are optimistic and subsidized if consumers are pessimistic. The optimal tax is monotonic in the difference in beliefs (and so is not a U-shaped function of consumers' beliefs, as in Section 3). This monotonicity property of the tax is emphasized in the merit goods literature (see, e.g., Sandmo, 1983, Besley, 1988). ${ }^{18}$ As a consequence, each consumer now behaves as if he shared the same beliefs $r$ as the regulator. This means that the prevention effort is the same as in the benchmark effort $a(r, r)$, so that taxation permits an efficient outcome.

\footnotetext{
${ }^{17}$ This aspect of the policy is discussed in Camerer et al. (2003), under the name of "asymmetric paternalism".

${ }^{18}$ See also the analysis of the paternalistic taxation in hyperbolic discounting models with addictive goods (O'Donoghue and Rabin, 2003, and Gruber and Koszegi, 2004). In these models, the addictive good may be viewed as a demerit good, and it is optimal to tax it.
} 
However, in the more realistic case where consumers have heterogeneous beliefs, efficiency would require the use of personalized taxes, a difficult task in practice. It may therefore be appropriate to turn to a second-best analysis by constraining the regulator to set a uniform tax on consumption. Then a uniform tax could only correct the average misperceptions, and the regulator would still have to deal with the remaining heterogeneity. Consequently, if consumers did not misperceive the risk on average, then the optimal tax would likely be close to zero, ${ }^{19}$ and thus quite useless. This reasoning shows that adjusting cleanup efforts may be a more powerful way to regulate than using uniform taxes (even under costless redistribution). Indeed, increasing prevention efforts can be simultaneously effective for both optimistic and pessimistic consumers, which could not be the case with a uniform taxation policy. This may support the observed important public investments in prevention together with the prevalent use of safety norms in the domain of risks policies, as opposed to other modes of regulation.

Obviously, there are other instruments than taxation to consider. Typically, in a world where citizens' perceptions are biased, information policies provide the most natural instruments to use. Consistent with the Portney's fable, we assumed that information policies have already been used in Happyville, and that, for some reasons, a belief perception gap persists between the Director and the citizens. Notice also that a powerful policy would be

\footnotetext{
${ }^{19}$ In the initial Happyville example that we considered in Section 2, the optimal uniform tax is exactly zero.
} 
to try to deceive citizens. For example the Director could pretend to use a particular cleanup effort level, but in reality choose a different one. If pretending is costless, such a policy of safety illusion is efficient, at the cost of morals.

Sunstein and Thaler (2003), in their discussion on libertarian paternalism, stress that many policies that would be useless in a world with consistent people may be effective in a world where citizens act inconsistently. Assume that the regulator knows the cause(s) of the inconsistency and can influence it, without affecting the freedom of choice. Suppose for instance that in Happyville the Director can manipulate the "framing" of the health-related problem and in turn change water consumption decisions. In that case, a libertarian paternalist Director may want to use a device to restore efficiency. Importantly, this device has the advantage of having no effect on the choices of consistent consumers, unlike the above-discussed safety norms or taxation.

\section{Conclusion}

An interesting policy question is whether consumers' beliefs about risks may explain the observed important public prevention programs. One direct explanation is that populist regulators primarily increase prevention efforts to reduce the worries of pessimistic agents, rather than to adequately respond to the risks in presence. $^{20}$ This paper has put forward another explanation:

\footnotetext{
${ }^{20}$ To illustrate, the Superfund program in the US and GMO regulatory policy in Europe are often presented as typical examples of populist policies.
} 
the mere fact that a regulator disagrees with the consumers' risk assessments is enough to support a more stringent prevention policy.

We have formally shown that this explanation may hold by examining the choices of a paternalistic regulator. This regulator maximizes consumers' welfare but computed with his own beliefs over the risk, $r$, and not with the consumers' beliefs $s$. We have shown then that the paternalist's prevention effort may increase due to the presence of two distinct effects: a protection and an encouragement effect. The protection effect may occur when consumers are optimistic $(s<r)$ so that risk-exposure is too high in the society. As a result, the regulator simply increases his effort to reduce the level of risk in the society. In contrast, the encouragement effect may occur when people are pessimistic $(s>r)$ so that risk-exposure is too low. A more stringent policy may be efficient in this case as well, since it reduces the perceived level of risk by consumers, and therefore helps increase consumption. ${ }^{21}$

However, the protection and encouragement effects typically go in opposite direction for a given consumer's beliefs. An important purpose of the analysis has been to compare their relative strength. Our most striking result is that a more stringent prevention policy may be always warranted both in a society with optimistic consumers or in a society with pessimistic consumers. This result holds if, as a response to an increase in safety, opti-

\footnotetext{
${ }^{21}$ To illustrate the protection effect, some examples may include home safety prevention, compulsory seatbelts, tolerance standard for pollutants or food additives, namely situations where people are prone to take too much risk. To illustrate the encouragement effect, an example could be the European stringent beef regulation in the late 90s that permitted to mitigate the huge decrease in beef consumption following the mad cow crisis.
} 
mistic consumers do not increase too much their consumption and pessimistic consumers do sufficiently increase their consumption. Hence the critical condition for the result to hold may be expressed in terms of the derivative of the consumption's elasticity. Consequently, a policy message of the paper is that, assuming that this condition on the consumption's elasticity is satisfied, one may provide an economic rationale for over-regulation of risks when people's beliefs about risks are distorted, no matter the direction of distortion, and absent any political economy considerations. 


\section{Appendix}

Proof of Proposition 1: from the linearity of $K$ in $r$, we have

$$
K(a, r, s)=K(a, s, s)+(r-s) K_{r}(a, ., s)
$$

where the second argument in the second term is omitted because $K$ is linear in $r$. Also the regulator and the agent agree on the choice of $b$ when they share the same beliefs; hence from the envelope theorem we get $K_{s}(a, s, s)=0$. Differentiating (12) with respect to $s$ and $a$, we thus get

$$
K_{a s}(a, r, s)=(r-s) K_{a r s}(a, ., s) .
$$

This implies that $K_{a s}(a, 0, s)=-s K_{a r s}(a, ., s)$, and thus

$$
K_{a s}(a, r, s)=\frac{s-r}{s} K_{a s}(a, 0, s)
$$

The assumption in the Proposition then ensures that $K_{a s}(a, r, s)$ is negative for $s<r$ and positive for $s>r$. This implies that $a(r, s)$ is U-shaped. Q.E.D.

Proof of Proposition 2: there remains to show result ii). From the definition of $j$ we have

$$
j_{a s}(a, s)=K_{a r}(a, ., s)+K_{a s}(a, s, s)=K_{a r}(a, ., s)
$$

because $K_{a s}(a, s, s)=0$. We thus get $j_{a s s}(a, s)=K_{a r s}(a, ., s)$. When this latter term is negative $a(r, s)$ is U-shaped from (13) and Proposition 1. Q.E.D. 


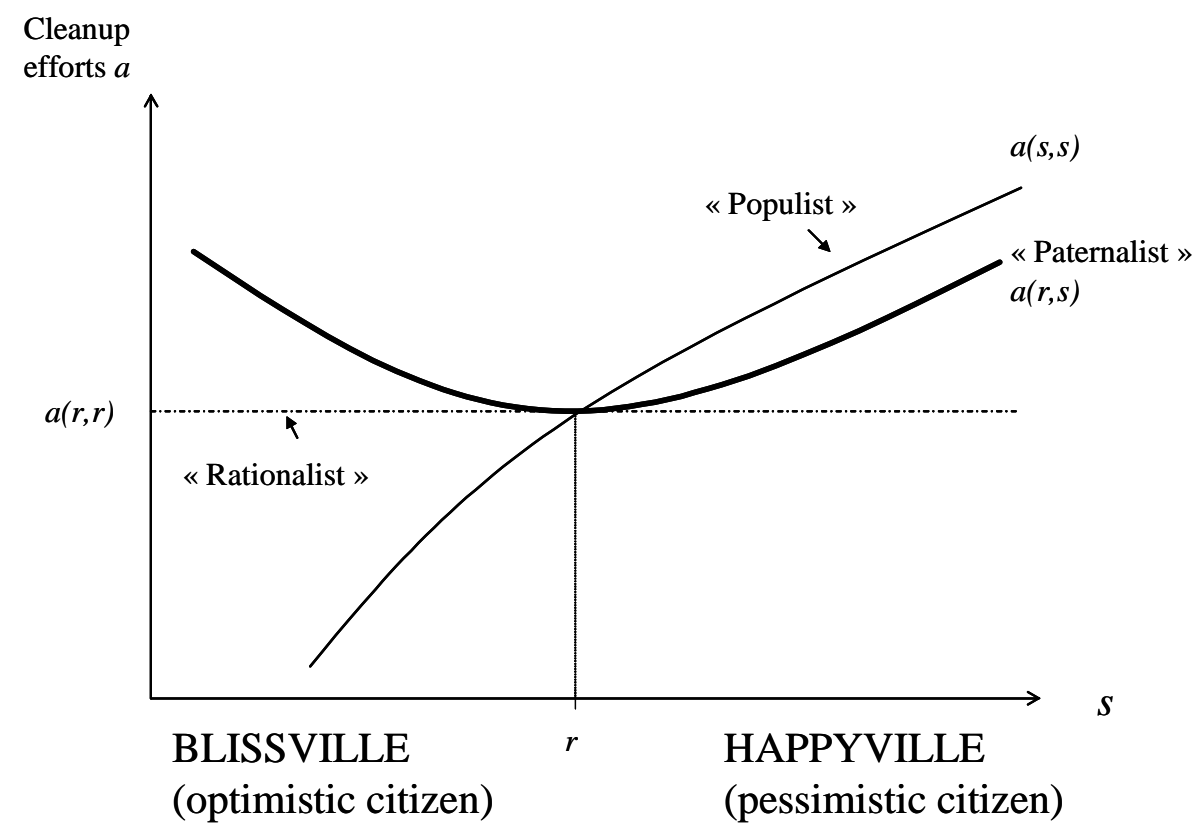

Figure 1:

Optimal cleanup effort as a function of the citizen's beliefs $s$ for three different Directors: the populist, the paternalist and the rationalist. 


\section{References}

Adler, M., 2005, Against "individual risk": A sympathetic critique of risk assessment, University of Pennsylvania Law Review, 153, 1121-1250.

Allen, F.W., 1987, Towards a holistic appreciation of risks: The challenge for communicators and policymakers, Science, Technology $\&$ Human Values, $12,138-43$.

Beck, U., Risk Society: Towards a New Modernity, Sage Publications, London.

Besley, T., 1988, A simple model for merit good arguments, Journal of Public Economics, 35, 371-383.

Boyer, M. and J.-J. Laffont, 1999, Toward a political theory of the emergence of environmental incentive regulation, Rand Journal of Economics, 30, $137-57$.

Breyer, S.G., 1993, Breaking the Vicious Circle: Toward Effective Risk Regulation, Harvard University Press.

Camerer, C., 1995, Individual decision making, In: Kagel, J.H. \& Roth, A.E. (eds.): Handbook of Experimental Economics, Princeton, NJ: Princeton University Press, 587-703.

Camerer, C., Issacharoff, S., Loewenstein, G., O’Donoghue, T. and M. Rabin, 2003, Regulation for conservatives: Behavioral economics and the case for "asymmetric paternalism", University of Pennsylvania Law Review, 
$51,1211-1254$.

Cropper, M.L., Evans, W.N., Berardi, S.J., Ducla-Soares, M.M. and P.R. Portney, 1992, The determinants of pesticide regulation: A statistical analysis of EPA decision making, Journal of Political Economy, 100, 175-97.

Gruber, J. and B. Koszegi, 2004, Tax incidence when individuals are time inconsistent: The case of cigarette excise taxes, Journal of Public Economics, 88, 1959-1988.

Kahneman, D., Slovic, P. and A. Tversky, 1982, Judgment under Uncertainty: Heuristics and Biases, Cambridge University Press.

Hahn, R., 1996, Editor, Risks, Costs, and Lives Saved-Getting Better Results from Regulation, Oxford University Press.

Hammitt, J.K., Wiener, J.B., Swedlow, B., Kall, D. and Z. Zhou, 2005, Precautionary regulation in Europe and in the United States: a quantitative comparison, Risk Analysis, 25, 1215-28.

Hird, J., 1994, Superfund: The Political Economy of Environmental Risk, John Hopkins University Press.

Margolis, H., 1996, Dealing with Risk: Why the Public and the Experts Disagree on Environmental Issues, University of Chicago Press, Chicago and London.

Nauges, C. and A. Thomas, 2000, Privately operated water utilities, municipality price negotiation, and estimation of residential water demand: the case of France, Land Economics, 76-1, 68-85.

O’Donoghue, T. and M. Rabin, 2003, Studying optimal paternalism, il- 
lustrated by a model of sin taxes, American Economic Review, Papers and Proceeedings, 93, 186-91.

Peltzman, S., 1975, The effects of automobile safety regulation, Journal of Political Economy, 83, 677-725.

Pollack, R.A., 1995, Regulating risks, Journal of Economic Literature, $33,179-91$.

Pollack, R.A., 1998, Imagined risks and cost-benefit analysis, American Economic Review, 88, 376-80.

Portney, P.R., 1992, Trouble in Happyville, Journal of Policy Analysis and Management, 11, 131-32.

Sandmo, A., 1983, Ex post welfare and the theory of merit goods, Economica, 50, 19-34.

Slovic, P., 2000, The Perception of Risk, Earthscan Publisher.

Spence, M., 1977, Consumer misperceptions, product failure and producer liability, Review of Economic Studies, 44, 561-572.

Sunstein, C.R., 2000, Cognition and cost-benefit analysis, in Cost-Benefit Analysis, Legal, Economic and Philosophical Perspectives, M.D. Adler and E.A. Posner (eds), University of Chicago Press.

Sunstein, C.R. and R.H. Thaler, 2003, Libertarian Paternalism, American Economic Review, Papers and Proceeedings, 93, 175-79.

Tengs, T.O., Adams, M.E., Pliskin, J.S., Gelb-Safran, D., Siegel, J.E., Weinstein, M.C. and J.D. Graham, 1995, Five-hundred life-saving interventions and their cost-effectiveness, Risk Analysis, 15, 369-90. 
Viscusi, W.K., 1998, Rational Risk Policy, Oxford University Press.

Viscusi, W.K., 2000, Risk equity, Journal of Legal Studies, 29, 843-71.

Viscusi, W.K. and J.T. Hamilton, 1999, Are risk regulators rational? Evidence from hazardous waste cleanup decisions, American Economic Review, $89,1010-1027$. 